\title{
Hydroinformatic Tools for Flood Risk Map Achievement
}

\author{
Erika Beilicci \\ POLITECHNICA University of Timisoara, \\ Department of Hydrotechnical Engineering, George Enescu 1/A, 300022 \\ Timisoara, Romania \\ Robert Beilicci \\ POLITECHNICA University of Timisoara, \\ Department of Hydrotechnical Engineering, George Enescu 1/A, 300022, \\ Timisoara, Romania \\ Ioan David \\ POLITECHNICA University of Timisoara, \\ Department of Hydrotechnical Engineering, George Enescu 1/A, 300022 \\ Timisoara, Romania
}

Received: December 31, 2020. Revised: March 5, 2021. Accepted: March 13, 2021. Published: March 23, 2021.

\begin{abstract}
Water Framework Directive and Flood Directive of European Commission establishes the need for preparation of flood risk maps for each member country on each important hydrographic basins. Based on these established the flood risk management plan (must be finalized by end of 2015), which is a communicator and disseminator tool of the knowledge gained during two previous stages across the horizontal structures of governmental and non-governmental bodies dealing with flood protection, flood mitigation and flood struggle in general. Flood risk management plans, considered as a communicator and disseminator tool across the horizontal structures of governmental and non-governmental bodies dealing with flood protection, flood mitigation and flood struggle in general. They mainly include proposals on how to reduce the losses of lives, property and environmental through flood prevention, protection of vulnerable areas and increased flood preparedness in each river basin. The way of processing of this flood risk management plans on IT platforms changes the information stream flow. Future development plans of regions and cities will get a proper guidance and platforms for future feasibility studies. In Romania, each state institution wants to improve the skills of their employees. There is a lack of specialists who has enough knowledge about the hydroinformatics, thus in everyday work there is a very limited use of such tool, meanwhile the work with complex problems has generated recently a need to use valuable tool.
\end{abstract}

Keywords- management, flood, flood risk management plan, hydroinformatic tools

\section{INTRODUCTION}

Floods are natural phenomena which cannot be prevented. Some human activities and climate change contribute to an increase in the likelihood and adverse impacts of flood events.

In order to have available an effective tool for information, as well as a valuable basis for priority setting and further technical, financial and political decisions regarding flood risk management, it is necessary to provide for the establishing of flood hazard maps and flood risk maps showing the potential adverse consequences associated with different flood scenarios, including information on potential sources of environmental pollution as a consequence of floods [1].
EU Member States should assess activities that have the effect of increasing flood risks. For to avoiding and reducing the adverse impacts of floods in the area concerned it is appropriate to provide flood risk management plans. Flood risk management plans should therefore take into account the particular characteristics of the areas they cover and provide for tailored solutions according to the needs and priorities of those areas, whilst ensuring relevant coordination within river basin districts and promoting the achievement of environmental objectives laid down in Community legislation [1].

Flood risk management plans should focus on prevention, protection and preparedness. With a view to giving rivers more space, they should consider where possible the maintenance and/or restoration of floodplains, as well as measures to prevent and reduce damage to human health, the environment, cultural heritage and economic activity. The elements of flood risk management plans should be periodically reviewed and if necessary updated, taking into account the likely impacts of climate change on the occurrence of floods [1].

Today, many national development and investment programs are needed to be done in relation to flood mitigation, adaptation and protection as well as to water scarcity and drought. It means huge infrastructural investments are and will running in these fields, particularly but not solely in the newly accessed countries and in water sector.

Each EU member state implementing Water Framework Directive (WFD) and Flood Directive (FD) 2007/60/EC, needs wide and interdisciplinary knowledge to be able to create areaadjusted solutions which provides solution for the local needs by understanding the national/country specific environmental processes.

In Europe, water managers must address the key requirements of the FD.

Flood risk management planning represents the most important element of EU Flood Directive. This is a communicator and disseminator of the knowledge gained during two previous stages across the horizontal structures of governmental and non-governmental bodies dealing with flood protection, flood mitigation and flood struggle in general, included public involvement in this process. These plans must 
be finalised as the final round of the first planning cycle of EU Flood Directive by the end of the year 2015. Flood risk management plans mainly include proposals on how to reduce the losses of lives, property and environmental through flood prevention, protection of vulnerable areas and increased flood preparedness in each river basin. The way of processing of this flood risk management plans on IT platforms changes the information stream flow.

Romania is one of most exposed countries to natural catastrophes, especially to floods, which have caused substantial damage during the last years. What currently occurs on the territory of Romania, and we are referring here to the two categories of hydrological phenomena - floods and droughts - is, on the one hand, the consequence of the global climatic changes on the regional and planetary level, and, on the second, of the human intervention on the specific landscape.

During the last years, despite the progresses we made in the field of scientific research and risk forecast, we cannot but notice a worldwide increase in the frequency of occurrence of catastrophic hydrological events, resulting in serious material damage and the loss of human lives. These undesired phenomena are often seen to be a consequence of natural events (magnetic storms, solar eruptions, El Niño phenomena) undoubtedly coupled with reckless human interventions, which led to changes of balance within the elements of the natural environment (massive land/woods clearing, without reforestation; the expansion of urban agglomeration, having as a result the waterproofing of an increasing number of areas; the building of dams, the watercourse regulation and the building of dykes; the drainage works, the excessive exploitation of water resources and, last but not least, the burning of combustible and the occurrence of the green house effect) [2].

\section{THE NEED TO USE HYDROINFORMATIC TOOLS FOR FLOOD RISK MAP ACHIEVEMENT}

In order to prevent these catastrophic hydrological phenomena, experts had to develop complex models of simulation based on elevated mathematical models of the dangerous hydrological phenomena triggering mechanisms of and their effects on the environment.

Considering the prevailing frequency of occurrence of floods, for areas of high flooding risk it is necessary that we make researches and studies that allow us to know the causes, the evolution and the effects of these phenomena on the environment. These researches require the achievement or the updating of topographical, geomorphological, climate and pedological studies regarding soil erosion, overland flow and other degradation, hydrological, hydrogeological, geotechnical processes, vegetation related and social / economic studies.

On the basis of these studies and developed complex simulation models we can elaborate the flood risk maps for all watercourses, with a high precision.

For achievement of flood risk maps is need to have engineers skilled in the field related to development of water management infrastructure as well as in system operation, who are familiar also with the newest technological achievements, capable to develop area-adjusted solutions by understanding the specific environmental processes.

\section{CLASSICAL MUSKINGUM METHOD}

The classic Muskingum methods is an hydrological methods for channel routing, which use the principle of continuity equation to solve the mass balance of inflow, outflow and the volume of storage. These methods of routing require a storage-stage-discharge-relation to determine the outflow for each time step. Hydrological methods involve numerical techniques that introduce translation or attenuation to an inflow hydrograph.

In classical Muskingum method, irregular non-permanent water movement is described by partial differential equations Saint-Venant. This system of equations is difficult to solve, the integration is numerical and is necessary to make in computing various simplifying assumptions. For problem solving is necessary to know the boundary conditions upstream and downstream sector of the studied river and its definition in a number of cross sections. Because in many cases do not provide profiles and unknown boundary conditions upstream and downstream sector of the river, have been imagined a series of methods to solve the problem of flood wave propagation based on the equation of continuity and need only wave hydrograph flood at the entrance to the river considered [3].

Based on the Muskingum model equations, a group of teachers from "Politechnica" University of Timisoara, Romania, developed a simulation program for flood wave propagation in natural river channels.

The Muskingum Method is a simple, approximate method to calculate the outflow hydrograph at the downstream end of the channel reach given the inflow hydrograph at the upstream end. No lateral inflow into the channel reach is considered.

Classical Muskingum method introduce in calculation of flood propagation in river bed a quite rigid relationship in displacement and attenuation of flood waves, especially because of the stability conditions imposed by the used integration method. In the study of flood waves propagation ant attenuation in the natural river beds was admitted the neunivocality of rating curve in the sector due to secondary phenomena accompanying the propagation of flood waves, such as the change of cross sections of the riverbed during the flood through sediments deposition or river bed erosion; absorption by dry soil of a volume of water that cannot be neglected when flood cover large areas; water free surface slope change for the same discharge, in case of increasing and decreasing of flood wave.

The Muskingum method assumes a single stage-discharge relationship. This assumption causes an effect known as hysteresis, which may introduce errors into the storage calculation. The hysteresis effect between reach storage and discharge is due to the different flood wave speeds during the rising and falling limb of the hydrograph. For the same river stage, the flood wave moves faster during the rising limb of the hydrograph. In spite of its simplicity and its wide applicability, the Muskingum method has the shortcoming of producing a 
negative initial outflow which is commonly referred to as 'dip' or 'reduced flow' at the beginning of the routed hydrograph. The method is restricted to moderate to slow rising hydrographs being routed through mild to steep sloping channels. This constraint restricts the Muskingum method even more by making the method not well suited for very mild sloping waterways where a looped stage-discharge rating may exist. The Muskingum method also ignores variable backwater effects such as downstream dams, constrictions, bridges and tidal influences. In small catchments, where measured inflow and outflow hydrographs are not available, or where a significant uncertainty and errors are reported for the outflow data, modeling the flow using this method is quite a source of errors, and the Muskingum method fails to simulate the flow hydrograph using this type of data [3].

\section{DUFLOW MODEL}

It is a one-dimensional program for quantitative and qualitative modeling of overland flow in open runways. It was developed by the International Institute for Hydraulic and Environmental Engineering (IHE) Delft, The Rijkswaterstaat (Public Works Department), the Tidal Water Division, The Hague, The Delft University of Technology, Holland.

DUFLOW is designed to cover a large range of applications, such as propagation of tidal waves in estuaries, flood waves in rivers, operation of irrigation and drainage systems, etc. Basically, free flow in open channel systems is simulated, where control structures like weirs, pumps, culverts and siphons can be included. As in many water management problems, the runoff from catchments areas is important; a simple precipitation-runoff relation is part of the model set-up in DUFLOW. The DUFLOW software consists of the following parts: DUFLOW water quantity (with this program one can perform unsteady flow computations in networks of open water courses) and DUFLOW water quality (this program is useful in simulating the transportation of substances in free surface flow and can simulate more complex water quality processes).

DUFLOW is based on the one-dimensional partial differential equation that describes non-stationary flow in open channels.

The application of this model supposes a plan of the study area for of the river network division and the hydrographical basin. The river network is divided into sectors of different lengths by nodes, in such a way that the linear sectors between two consecutive nodes, following the axe curves of the river bed. In each node, we need to show the bed level and the width of the water mirror on different levels. The area of hydrographical basin is delimited by the highest slope line, and, subsequently, successively, the associated flow areas which will connect in nodes [4].

The results from simulation with DUFLOW are: the variation of water levels and water discharges in each node of network.

Unlike Muskingum method, which based on a relatively simple equation, the DUFLOW model is a numerical model with a more complex theoretical base. The numerical methods offer multiple possibilities related to the most complex and difficult problems of research, developed in physics of hydraulic phenomena's. The numerical calculus permit the knowledge of physical phenomena's with sufficient accuracy, so most times, checking on laboratory models is no longer necessary. The application of this model supposes a plan of the studied area for the division of the hydrographical network and the basin.

Muskingum method is applicable only for sectors of watercourses where not exist lateral inflows like tributaries, while DUFLOW can apply for a whole river system. The model takes into account the existing hydraulic structures on watercourses. The hydrographical network is divided into sectors of different lengths by nodes, so that the linear sectors between two consecutive nodes follow the axe curves of the rivers thalweg. In each node, we need to show the thalweg level and the width of the water mirror on different levels. The area of the hydrographical basin is delimited by the highest slope line, and, subsequently, successively, the associated flow areas which will connect in nodes [5].

\section{HYDROLOGIC ENGINEERING CENTERS RIVER ANALYSIS SYSTEM (HEC-RAS) MODEL}

HEC-RAS is a computer program that models the hydraulics of water flow through natural rivers and other channels. The program is one-dimensional, meaning that there is no direct modeling of the hydraulic effect of cross section shape changes, bends, and other two- and three-dimensional aspects of flow. The program was developed by the US Department of Defense, Army Corps of Engineers in order to manage the rivers, harbors, and other public works under their jurisdiction; it has found wide acceptance by many others since its public release in 1995 .

The basic computational procedure of HEC-RAS for steady flow is based on the solution of the one-dimensional energy equation. Energy losses are evaluated by friction and contraction / expansion. The momentum equation may be used in situations where the water surface profile is rapidly varied. These situations include hydraulic jumps, hydraulics of bridges, and evaluating profiles at river confluences.

For unsteady flow, HEC-RAS solves the full, dynamic, 1-D Saint Venant Equation using an implicit, finite difference method. The unsteady flow equation solver was adapted from Dr. Robert L. Barkau's UNET package.

HEC-RAS is equipped to model a network of channels, a dendritic system or a single river reach. Certain simplifications must be made in order to model some complex flow situations using the HEC-RAS one-dimensional approach. It is capable of modeling subcritical, supercritical, and mixed flow regime flow along with the effects of bridges, culverts, weirs, and structures.

HEC-RAS is a computer program for modeling water flowing through systems of open channels and computing water surface profiles. HEC-RAS finds particular commercial application in floodplain management and flood insurance studies to evaluate floodway encroachments. Some of the additional uses are: bridge and culvert design and analysis, 
levee studies, and channel modification studies. It can be used for dam breach analysis, though other modeling methods are presently more widely accepted for this purpose.

HEC-RAS has merits, notably its support by the US Army Corps of Engineers, the future enhancements in progress, and its acceptance by many government agencies and private firms. It is in the public domain and peer-reviewed. The use of HECRAS includes extensive documentation, and scientists and engineers versed in hydraulic analysis should have little difficulty utilizing the software.

Users may find numerical instability problems during unsteady analyses, especially in steep and/or highly dynamic rivers and streams. It is often possible to use HEC-RAS to overcome instability issues on river problems. HEC-RAS is a 1-dimensional hydrodynamic model and will therefore not work well in environments that require multi-dimensional modeling. However, there are built-in features that can be used to approximate multi-dimensional hydraulics [6].

\section{MIKE 11 MODEL}

MIKE 11 is a professional engineering software package for simulation of one-dimensional flows in estuaries, rivers, irrigation systems, channels and other water bodies. MIKE 11 is a 1-dimensional river model. It was developed by DHI Water - Environment • Health, Denmark.

The Hydrodynamic Module (HD), which is the core component of the model, contains an implicit finite-difference 6-point Abbott-Ionescu scheme for solving the Saint-Venant's equations. The formulation can be applied to branched and looped networks and flood plains. HD module provides fully dynamic solution to the complete nonlinear 1-D Saint Venant equations, diffusive wave approximation and kinematic wave approximation, Muskingum method and Muskingum-Cunge method for simplified channel routing. It can automatically adapt to subcritical flow and supercritical flow. It has ability to simulate standard hydraulic structures such as weirs, culverts, bridges, pumps, energy loss and sluice gates.

The MIKE 11 is an implicit finite difference model for one dimensional unsteady flow computation and can be applied to looped networks and quasi-two dimensional flow simulation on floodplains. The model has been designed to perform detailed modeling of rivers, including special treatment of floodplains, road overtopping, culverts, gate openings and weirs. MIKE 11 is capable of using kinematic, diffusive or fully dynamic, vertically integrated mass and momentum equations. Boundary types include Q-h relation, water level, discharge, wind field, dambreak, and resistance factor. The water level boundary must be applied to either the upstream or downstream boundary condition in the model. The discharge boundary can be applied to either the upstream or downstream boundary condition, and can also be applied to the side tributary flow (lateral inflow). The lateral inflow is used to depict runoff. The Q-h relation boundary can only be applied to the downstream boundary. MIKE 11 is a modeling package for the simulation of surface runoff, flow, sediment transport, and water quality in rivers, channels, estuaries, and floodplains.
MIKE 11 has long been known as a software tool with advanced interface facilities. Since the beginning MIKE11 was operated through an efficient interactive menu system with systematic layouts and sequencing of menus. It is within than framework where the latest 'Classic' version of MIKE 11 version 3.20 was developed.

The new generation of MIKE 11 combines the features and experiences from the MIKE 11 'Classic' period, with the powerful Windows based user interface including graphical editing facilities and improved computational speed gained by the full utilization of 32-bit technology.

The computational core of MIKE 11 is hydrodynamic simulation engine, and this is complemented by a wide range of additional modules and extensions covering almost all conceivable aspects of river modeling.

MIKE 11 has been used in hundreds of application around the world. Its main application areas are flood analysis and alleviation design, real-time flood forecasting, dam break analysis, optimisation of reservoir and canal gate/structure operations, ecological and water quality assessments in rivers and wetlands, sediment transport and river morphology studies, salinity intrusion in rivers and estuaries [7].

\section{EXAMPLE OF FLOOD RISK MAP ACHIEVEMENT USING MIKE 11}

To exemplify of flood risk map achievement with MIKE 11 hydroinformatic tools was considered a sector of Crasna River, located in northwestern Romania. Considered sector have a length of $64 \mathrm{~km}$, representative cross sections are considered in the right of localities Supuru de Jos, Craidorolt, Domanesti and Berveni, the border with Hungary (Fig. 1). Cross sections have been raised by the Romanian Waters, Somes-Tisa Water Basin Administration.

The input data are: area plan with location of cross sections (Fig. 2); cross sections topographical data and roughness of river bed (Fig. 3); flood discharge hydrograph in section Supuru de Jos (Fig. 4).

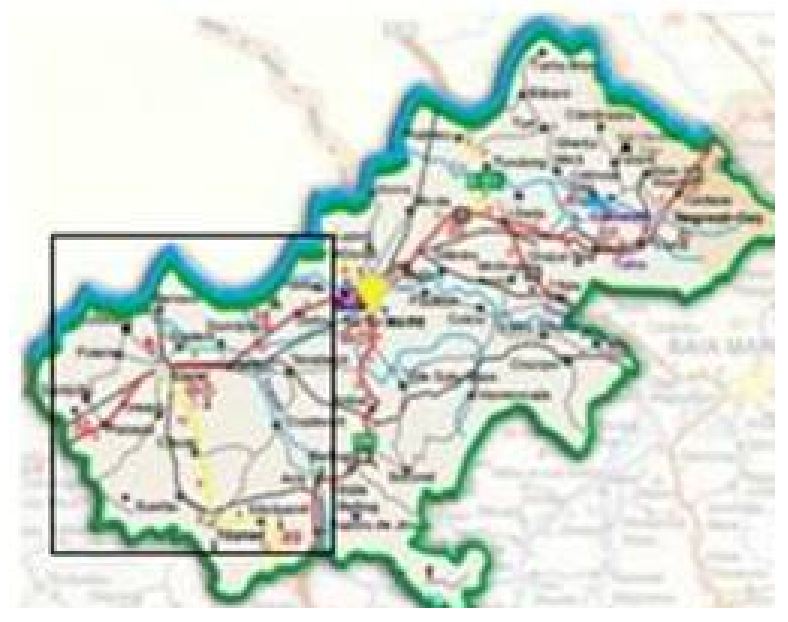

Fig. 1. Area plan. 


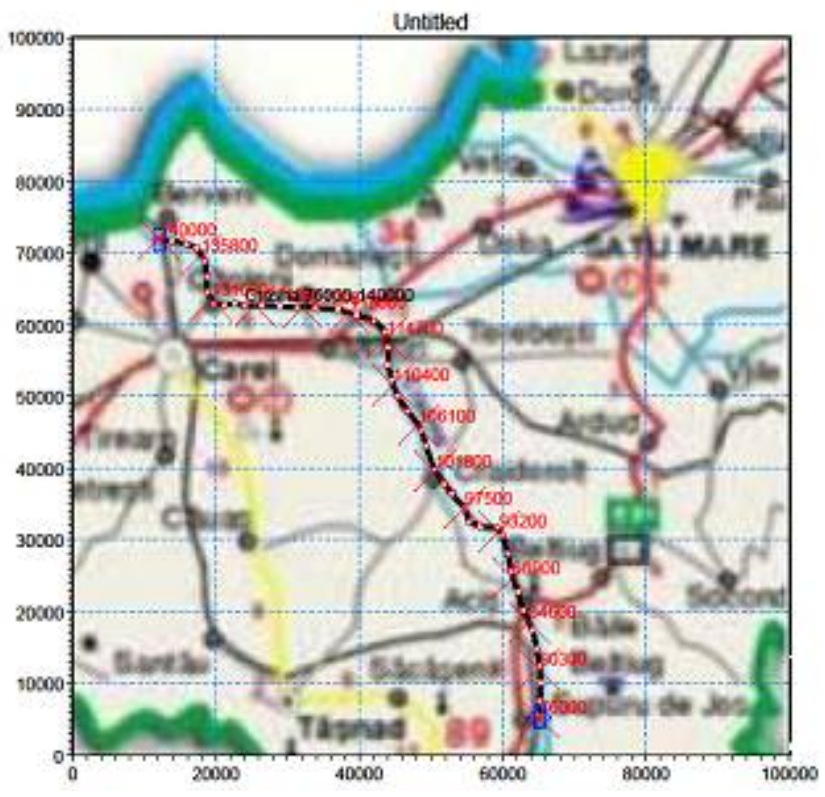

Fig. 2. Area plan with location of cross sections.

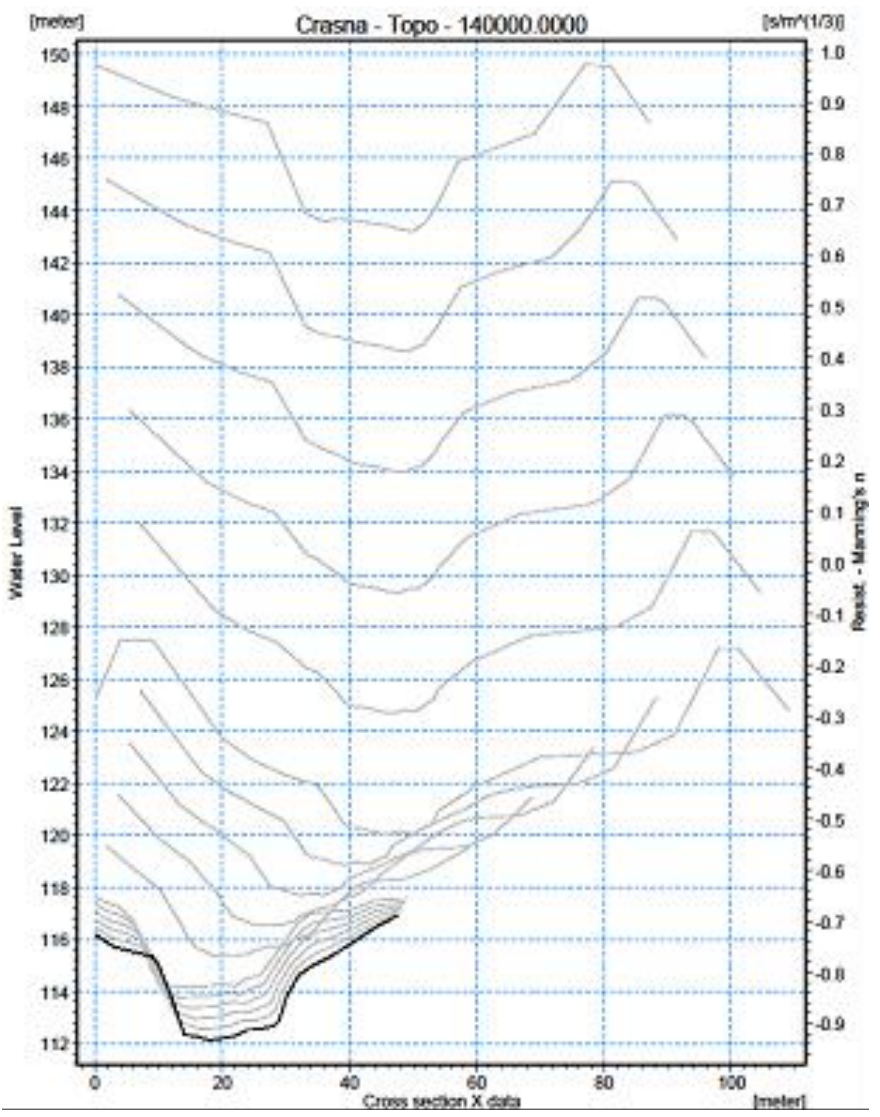

Fig. 3. Cross sections topographical data.

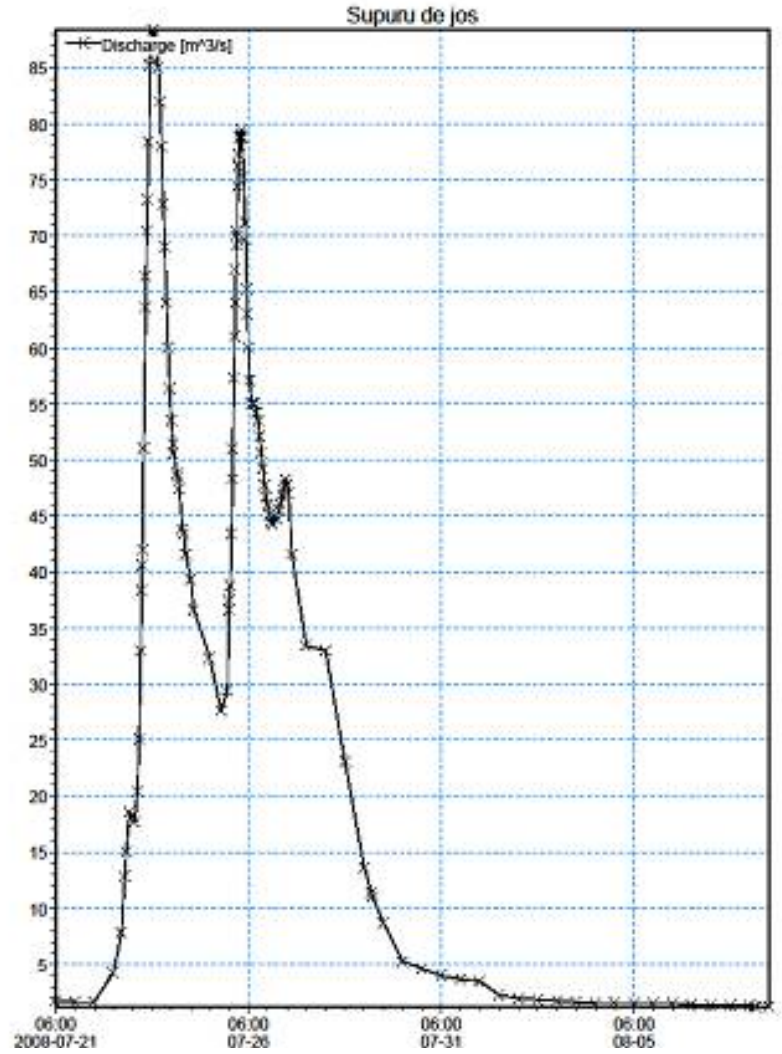

Fig. 4. Flood discharge hydrograph in section Supuru de Jos.

After simulation with MIKE 11 result the water level in each cross sections (Fig. 5) and in Fig. 6 are show the Domanesti cross section, where the water level exceeds the level of dike and flood village. Based on contour maps we can establish the flooded area (Fig. 7), the flood risk map for the maximum discharge $88,4 \mathrm{~m} 3 / \mathrm{s}$. For comparison of simulations with measured values, t-test of student method and X-square test was used for the three sections corresponding localities Craidorolt, Domanesti and Berveni. The test results are shown in Figure 8.

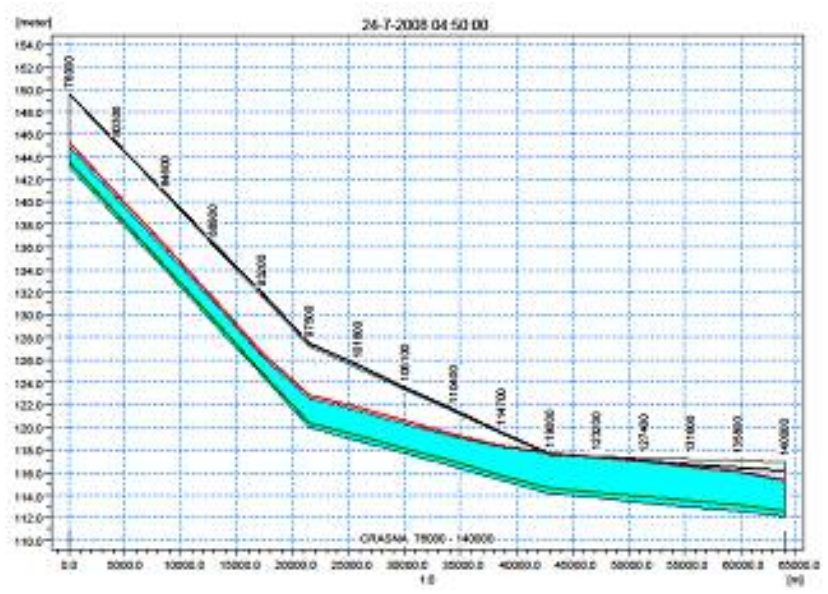

Fig. 5. Water level in each cross sections. 


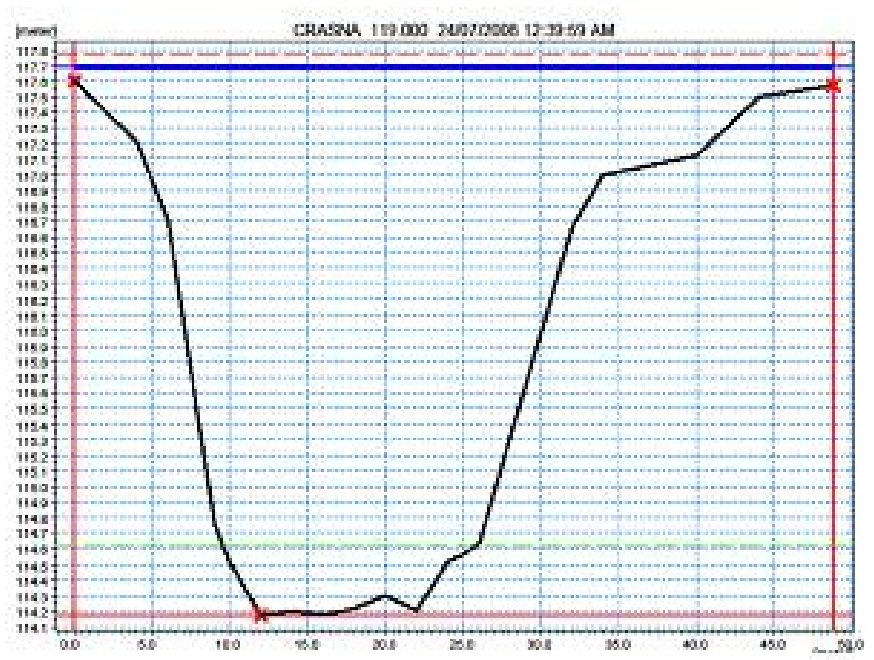

Fig. 6. Maximum water level in Domanesti cross section.

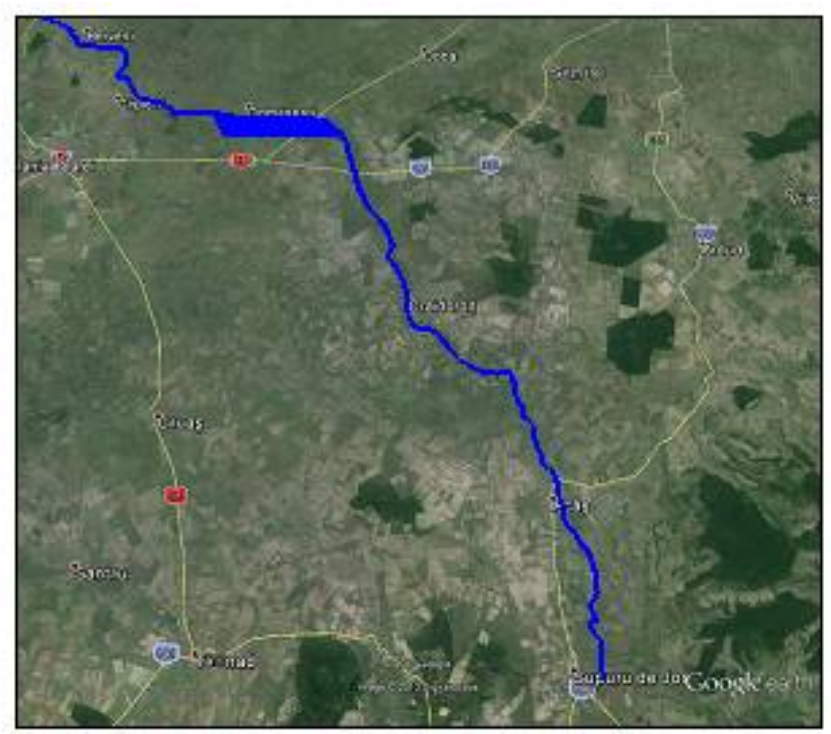

Fig. 7. The flood risk map for the maximum discharge $88,4 \mathrm{~m} 3 / \mathrm{s}$.

\begin{tabular}{|c|c|c|c|c|c|c|}
\hline \multirow{2}{*}{$\begin{array}{l}\text { 6-Test: Two-Sample } \\
\text { Attuming tnequal } \\
\text { Variancet }\end{array}$} & \multicolumn{2}{|c|}{ Craidorolt } & \multicolumn{2}{|c|}{ Domaneztí } & \multicolumn{2}{|c|}{ Benveni } \\
\hline & Calcolare & Areasared & Cakcolare & Measaved & Cakcolare & Measoures \\
\hline Mean & 17.683 & 63,415 & 15315 & 44949 & 15.869 & 40,776 \\
\hline Vyianst & 758.179 & 1749.009 & 374023 & 323.894 & $\$ 16.414$ & 475.916 \\
\hline Cbservationa & 445 & 125 & 445 & 173 & 445 & 96 \\
\hline $\begin{array}{c}\text { Hypothevised Meas } \\
\text { Diffestence }\end{array}$ & \multicolumn{2}{|r|}{0} & \multicolumn{2}{|r|}{0} & \multicolumn{2}{|c|}{0} \\
\hline$d 4$ & \multicolumn{2}{|c|}{141} & \multicolumn{2}{|c|}{335} & \multicolumn{2}{|c|}{133} \\
\hline t Stat & \multicolumn{2}{|c|}{.11 .120} & \multicolumn{2}{|c|}{.17 .993} & \multicolumn{2}{|c|}{.10 .260} \\
\hline$P(T<-4)$ ont-12: & \multicolumn{2}{|c|}{$2.556578-21$} & \multicolumn{2}{|c|}{$2.005916-51$} & \multicolumn{2}{|c|}{$7,465415-19$} \\
\hline t Critical one-tail & \multicolumn{2}{|c|}{1.656} & \multicolumn{2}{|c|}{1.549} & \multicolumn{2}{|c|}{1.656} \\
\hline$P(T<-a t)$ twe-tal & \multicolumn{2}{|c|}{$5,81314 \mathrm{E}-21$} & \multicolumn{2}{|c|}{ 4.01183E.51 } & \multicolumn{2}{|c|}{ 1.49308E.18 } \\
\hline t Critisal t=o-tail & \multicolumn{2}{|c|}{1977} & \multicolumn{2}{|c|}{1967} & \multicolumn{2}{|c|}{1.978} \\
\hline X-squase tave & \multicolumn{2}{|c|}{0.875} & \multicolumn{2}{|c|}{0.862} & \multicolumn{2}{|c|}{0.881} \\
\hline
\end{tabular}

Fig. 8. T-test and X-square test results

\section{CONCLUSIONS}

Besides the models mentioned above, have been developed over the years other models applied in the preparation of flood risk maps. In Romania, most flood risk maps were prepared using HEC-RAS and MIKE 11 models, which show a high degree of confidence.
Throughout the Community Countries different types of floods occur, such as river floods, flash floods, urban floods and floods from the sea in coastal areas. The damage caused by flood events may also vary across the countries and regions of the Community. Hence, objectives regarding the management of flood risks should be determined by the Member States themselves and should be based on local and regional circumstances. In each river basin district or unit of management the flood risks and need for further action should be assessed. In order to have available an effective tool for information, as well as a valuable basis for priority setting and further technical, financial and political decisions regarding flood risk management, it is necessary to provide for the establishing of flood hazard maps and flood risk maps showing the potential adverse consequences associated with different flood scenarios, including information on potential sources of environmental pollution as a consequence of floods.

Member States should assess activities that have the effect of increasing flood risks. Flood risk management plans should therefore take into account the particular characteristics of the areas they cover and provide for tailored solutions according to the needs and priorities of those areas, whilst ensuring relevant coordination within river basin districts and promoting the achievement of environmental objectives laid down in Community legislation. Member States should base their assessments, maps and plans on appropriate 'best practice' and 'best available technologies' not entailing excessive costs in the field of flood risk management [1].

\section{ACKNOWLEDGMENT}

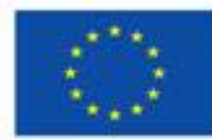

\section{Lifelong Learning Programme}

This project has been funded with support from the European Commission. This publication [communication] reflects the views only of the author, and the Commission cannot be held responsible for any use which may be made of the information contained therein.

\section{REFERENCES}

[1] Directive 2007/60/EC of the European Parliament and of the Council of 23 October 2007 on the assessment and management of flood risks.

[2] I. David, Zs. Nagy, E. Beilicci, T. Kramer, A. Szilagyi, "Development of knowledge centers for life-long learning by involving of specialists and decision makers in flood risk management using advanced hydroinformatic tools", Lifelong Learning Programme Leonardo da Vinci, Submission ID 260243, Submission local date (Brussels), 201102-28, Hash code 5BA440F7658CABFE, Form id. 5BA440F7.

[3] S. Elbashir, "Flood Routing in Natural Channels Using Muskingum Methods", Dublin Institute of Technology, Ireland, pp. 18-26, 2011.

[4] DUFLOW Reference Manual, Version 3.5, Stowa / MX System, Holland, 2002.

[5] E. Beilicci, R. Beilicci, „A comparative analysis of two flood wave propagation models", International Multidisciplinary 12th Scientific GeoConference SGSM, Albena, Bulgaria, 2012, vol. III, pp. 523-530.

[6] HEC-RAS Reference manual, US Army Corps of Engineers, Hydrologic Engineering Centers, 2010.

[7] MIKE 11 - A modelling system for rivers and channels, Short introduction and tutorial, DHI, Horsholm, Denmark, 2011.

\section{Creative Commons Attribution License 4.0 (Attribution 4.0 International, CC BY 4.0)}

This article is published under the terms of the Creative Commons Attribution License 4.0

https://creativecommons.org/licenses/by/4.0/deed.en_US 